\title{
Purification of anterior pituitary and hypothalamic hormones
}

\author{
P. J. LOWRY, C. MCLEAN, R. LUMLEY JONES, AND N. SATGUNASINGAM \\ From the Department of Chemical Pathology, St Bartholomew's Hospital, London EC1A 7BE
}

Pure preparations of pituitary and hypothalamic hormones are needed mainly for (1) their chemical characterisation, which increases our understanding of their biochemistry and makes their synthesis possible; (2) replacement therapy, in which contamination with other pituitary hormones is undesirable; and (3) the development of specific diagnostic assays.

Pituitary hormones were first isolated from tissue by fractionation procedures involving precipitation by various salts and solvents. However, the development of chromatographic materials has lessened the problems of fractionation and purification. The strategy usually depends on the particular pituitary hormone or class of pituitary hormone. Since the hypothalamic hormones are present in very low concentrations their isolation poses quite difficult problems, which will be discussed at the end of the paper.

Before trying to isolate a hormone an assay must be available. Ideally, this should be a biological one which can measure the potency of material obtained at each fractionation stage. In the early days this was impossible as the assay sometimes took longer than the isolation procedure. Recently, the development of biological assays using tissue slices and isolated cells has made a quick assessment of biologically active fractions possible. Radioimmunoassay is another rapid method but has the obvious limitation that the hormone must have been purified on an earlier occasion for the assay to have been developed.

Since anterior pituitary hormones are speciesspecific we will restrict discussion to the isolation of the human hormones, as these are obviously more important clinically.

\section{Human growth hormone (HGH)}

The isolation of human growth hormone was a very important advance since it is now used to treat children with retarded growth due to hormone deficiency. Growth hormone from domestic animals such as the ox is virtually inactive in man, and soa continuous supply of hormone purified from human glands is essential.
HGH is a protein with a molecular weight of abou? 21000 . It consists of a single polypeptide chain ợ 191 residues which contains two intramoleculae disulphide bridges. In 1959 Raben devised an isolation procedure for $\mathrm{HGH}$ from acetone-dried glands, which are extracted with glacial acetic acid a $\vec{P}$ $70^{\circ} \mathrm{C}$. The soluble extract is treated with sodiunt chloride and acetone. The precipitate which forms is discarded and crude growth hormone is precipies tated by the addition of ethyl ether. The precipitate is dissolved in $0.1 \mathrm{M}$ acetic acid and treate twice with oxycellulose to remove ACTH. The supernatant is made $0 \cdot 1 \quad M$ with potassium hydroxide and the $\mathrm{pH}$ is adjusted to 8.5. 辛e resulting precipitate is discarded and growth hore mone finally precipitated by the addition of an eqसa volume of ethanol at $5^{\circ} \mathrm{C}$.

Although this procedure is rather rigorous an likely to produce denatured protein its use led to the first successful treatment of children. Unfortunately long-term therapy failed in several cases owing to the immunogenicity of the material.

A different isolation procedure, again using ace tone-dried pituitaries, was described by Wilhelm (1961) and later modified by Mills et al. (1969) Preliminary extraction with $6 \%$ ammonium acetate. in $40 \%$ ethanol removes the glycoprotein hormonesi growth hormone is extracted from the residue wit $0.1 \mathrm{M} \mathrm{NaOH}$. After adjusting the $\mathrm{pH}$ to 10 the extraction is continued overnight. Adjusting the $\mathrm{pH}$ to 7 with $\mathrm{HCl}$ results in a precipitate, which is dis? carded. The supernatant is made $0.8 \mathrm{M}$ with ammo nium sulphate, and again the resulting precipitate $\mathbb{P}$ discarded. Growth hormone is precipitated by malfs ing the supernatant $2 \mathrm{M}$ with ammonium sulphate After centrifugation the crude $\mathbf{H G H}$ is dialysed against distilled water and dissolved in $0.1 \mathrm{M}$ acetic acid. Washed oxycellulose is added to remove ACTH and the supernatant adjusted to $\mathrm{pH} 3.7$ with $\mathrm{NaOH}$ Ammonium sulphate is added to give a final molarity of 1.25 and the resulting precipitate, clinical grado HGH, is dialysed and freeze dried. The final yield of growth hormone is about $8 \mathrm{mg}$ per gland, which i⿱ twice that obtained with the Raben procedure. 


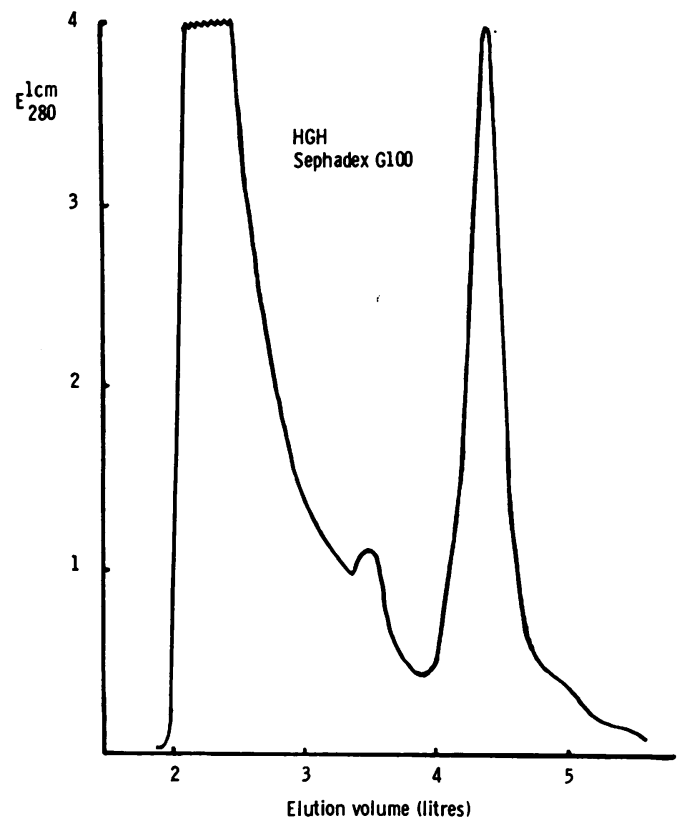

Fig. 1 Separation of monomeric human growth hormone by gel filtration on Sephadex $G 100(100 \times 10 \mathrm{~cm})$ using $50 \mathrm{mM}$ tris-acetate buffer $\mathrm{pH} 8 \cdot 5$. Monomeric growth hormone elutes between 4 and 5 litres.

Roos et al. (1963) used frozen pituitary glands as their study material. Growth-promoting activity is more easily extracted from tissue which has not been dried with acetone, and consequently they needed only to extract with phosphate buffer at $\mathrm{pH} 6 \cdot 2$. The soluble extract is adjusted to $\mathrm{pH} 7$ and $\mathrm{HGH}$ precipitated by making the solution $2 M$ with ammonium sulphate. After redissolving the precipitate in phosphate buffer containing $\mathrm{NaCl}$ growth hormone is further purified by gel filtration on Sephadex G100. This method forms the basis of the commercial production of HGH by Kabi in Sweden.

A new method for isolating highly purified and potent $\mathrm{HGH}$ from frozen human pituitary glands has recently been devised by Jones et al. (1977). It takes advantage of the high solubility of $\mathrm{HGH}$ at $\mathrm{pH}$ values just above neutrality and its extreme insolubility at its isoelectric point. Proteolytic inhibitors are used in the initial extraction to ensure the integrity and yield of the final product. In outline, the method, with all the procedures carried out at $4^{\circ} \mathrm{C}$, is as follows: frozen pituitary glands are homogenised in $50 \mathrm{mM}$ tris- $\mathrm{HCl}$ buffer $\mathrm{pH} 8.5$ containing $1.5 \mathrm{mmol}$ phenylmethylsulphonyl fluoride, $5 \mathrm{mmol}$ EDTA, and $10 \mathrm{mmol} \mathrm{Na}_{2} \mathrm{HPO}_{4}$. The supernatant is adjusted to pH 6 with acetic acid and allowed to stand over- night. The precipitate is discarded, the $\mathrm{pH}$ of the solution is further lowered to 4.9 , and the supernatant is made $10 \%$ with ethanol. Allowing the mixture to stand overnight precipitates crude growth hormone. After washing with buffer at $\mathrm{pH} 4.9$ the precipitate is dissolved in tris-acetate buffer $\mathrm{pH} 8.5$ by stirring overnight. The resulting supernatant is submitted to hollow fibre concentration and filtered through a bacteriological membrane. The solution is then submitted to gel filtration on Sephadex G100 at $8^{\circ} \mathrm{C}$. Monomeric human hormone appears in the effluent after about half a bed volume has been eluted (Fig. 1). Fractions containing $\mathrm{HGH}$ are loaded directly on to a DEAE cellulose column equilibrated with $50 \mathrm{mM}$ ammonium acetate buffer $\mathrm{pH} 8 \cdot 5$. After washing the column with $50 \mathrm{mM}$ and $100 \mathrm{mM}$ ammonium acetate buffer $\mathrm{HGH}$ is eluted with $200 \mathrm{mM}$ ammonium acetate buffer pH 8.3 (Fig. 2) and the fractions are pooled and freeze dried. The overall yield of monomeric growth hormone is about $60 \%$ and the final product, $6 \mathrm{mg}$ per gland, has a potency more than double that of existing clinical grade preparations.

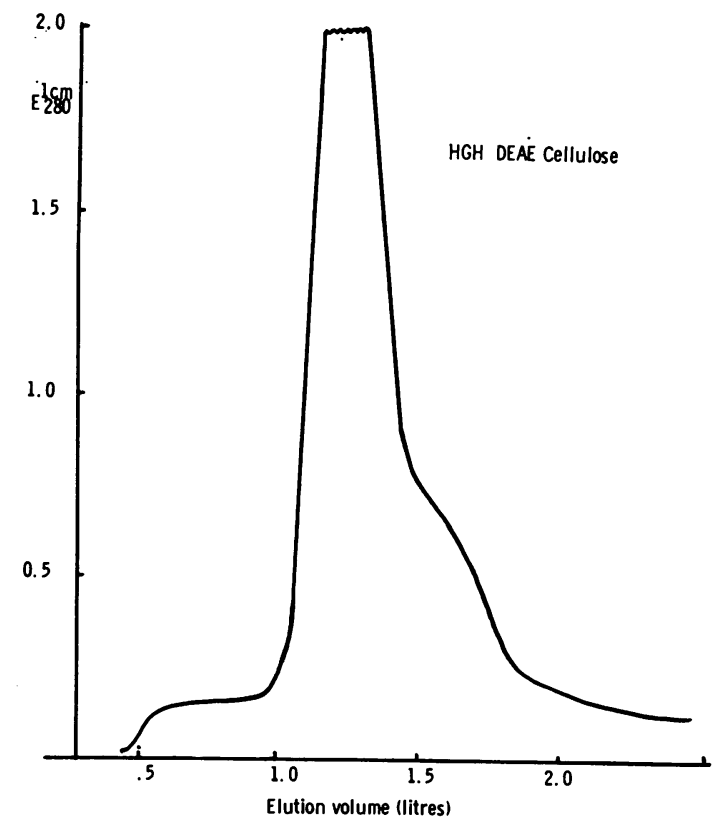

Fig. 2 Purification of monomeric human growth hormone using DEAE cellulose $(20 \times 5 \mathrm{~cm})$. The column is equilibrated and washed with $50 \mathrm{mM}$ ammonium acetate pH 8.5, washed with $100 \mathrm{mM}$ ammonium acetate pH 8.3, and growth hormone eluted with $200 \mathrm{mM}$ ammonium acetate $\mathrm{pH} 8 \cdot 3$. 


\section{Prolactin}

Ten years ago it was thought that human prolactin might not exist, as attempts to isolate it invariably resulted in fractions rich in growth hormone-like material. Furthermore, certain preparations of human growth hormone had a lactogenic activity nearly equivalent to that of early preparations of human prolactin. Prolactin has certain structural similarities with growth hormone. They have about the same molecular weight and bear some sequence homology, though the concentration of prolactin in pituitary glands is much less than that of growth hormone.

During an electrophoretic investigation of proteins from the pituitary of a pregnant woman a band of protein was identified which had the characteristics of prolactin. This led to the first purification of human prolactin from frozen human pituitary glands by Lewis et al. (1971). Initial extraction with saline removed a large proportion of the growth hormone. Prolactin was extracted from the residue at pH 9.5 in $60 \%$ ethanol and precipitated with $85 \%$ ethanol at $\mathrm{pH}$ 6. Chromatography of the redissolved precipitate was carried out on Sephadex G100 and DEAE cellulose. Hwang et al. (1972) removed insoluble proteins with ammonium acetate at $\mathrm{pH}$ झु and extracted the residue at $\mathrm{pH} 10 \cdot 5$. Ethano fractionation was carried out on the supernatant at pH 8.5 and the fraction which precipitated betweef $25 \%$ and $85 \%$ ethanol was redissolved in alkali and submitted to chromatography on Sephadex G100 蛅 pH 9. Final purification was achieved by ion exchange chromatography on DEAE and CM cellulose.

Satgunasingam and Lowry (unpublished observof tions) have recently been able to obtain a prolactini rich fraction from the growth hormone purificatio $\overrightarrow{\mathrm{m}}$ procedure of Jones et al. (1977). Prolactin is eluted during the final stage of growth hormone purificatios on DEAE cellulose by the $100 \mathrm{mM}$ ammoniurif acetate buffer wash. Prolactin-rich fractions from this wash are diluted twice and reapplied to DEAE cellulose. Changing to $75 \mathrm{mM}$ elutes prolactin in pure form (Fig. 3).

\section{Glycoprotein hormones}

This class of hormones comprises luteinizines hormone (LH), follicle-stimulating hormone (FSH and thyrotrophin (TSH). LH, FSH, and TSH are structurally very similar. They each have a mole cular weight of about 30000 , contain covalegt\$

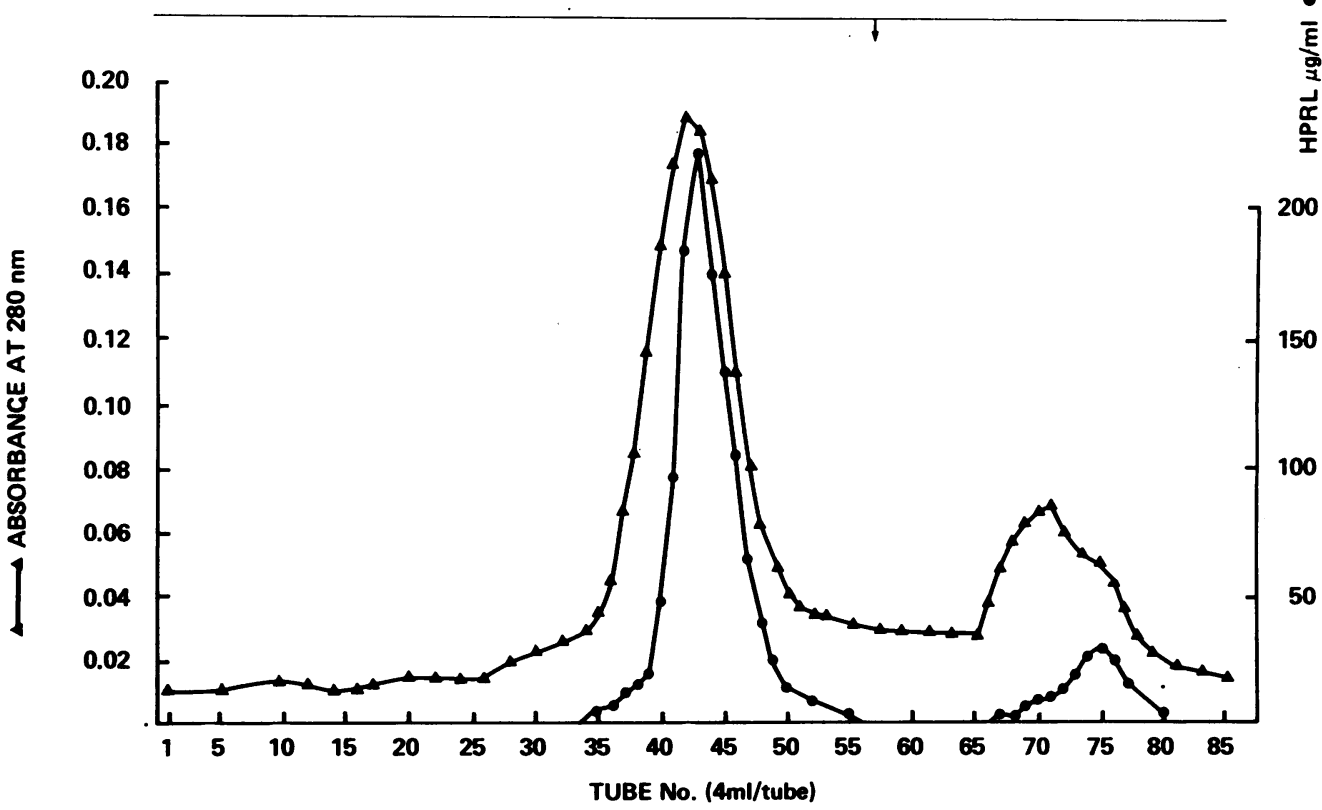

Fig. 3 Purification of human prolactin using DEAE cellulose $(25 \times 1.5 \mathrm{~cm})$. The column is equilibrated with $50 \mathrm{mM}$ ammonium acetate $\mathrm{pH} 8.5$ and prolactin eluted with $75 \mathrm{mM}$ ammonium acetate $\mathrm{pH} 8.5$. $\Delta-\Delta$ Elution of protein $\left(E_{\mathrm{200}}^{\mathbf{1 0 m}}\right)$. - Elution of prolactin (radioimmunoassay). 

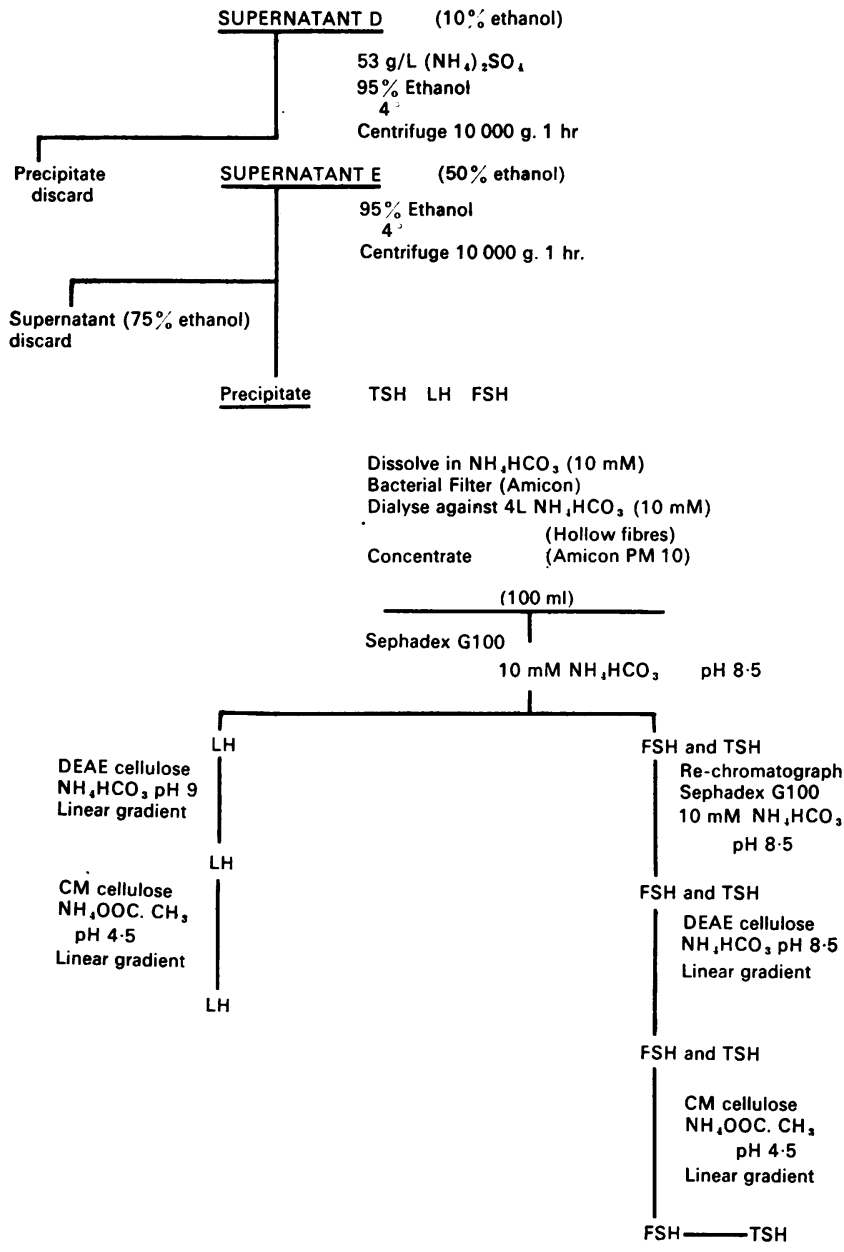

Fig. 4 Fractionation and purification of human pituitary glycoprotein hormones after removal of growth hormone. bonded polysaccharide moieties, and are composed of two subunits $\alpha$ - and $\beta$-. The subunits can be dissociated by strong non-covalent bond-breaking reagents. Neither subunit has significant biological activity but incubation at neutral $\mathrm{pH}$ leads to recombination and the reappearance of biological activity. Additionally, the $\beta$-subunit of $\mathbf{L H}$, for example, will combine with the $\alpha$-subunit of TSH to give a product which resembles LH in its biological activity. Similar results are obtained with recombination of the $\beta$-subunits of TSH and FSH with other $\alpha$-subunits, the $\beta$-subunit dictating the biological activity.

It is no surprise that the amino-acid sequences of the $\alpha$-subunits are very similar if not identical. The similarity of the polysaccharide moieties which are covalently linked to these subunits, usually via the side chain of asparagine residues, has yet to be confirmed. Interestingly, however, there is more identity of the $\beta$-subunit than of the $\alpha$-subunit of the same hormone isolated from different species. In other words, while the $\alpha$-subunit is species specific the $\beta$-subunit is biologically specific (Vaitukaitus and Ross, 1974).

Again we shall deal only with the isolation of these hormones from human tissue. The scarcity of human pituitary tissue makes it expedient to isolate these hormones from glands which have been collected mainly for the isolation of growth hormone. Hartree (1966) uses the supernatant from the initial extraction of acetone-dried glands, increasing the ethanol concentration of the supernatant and precipitating a glycoprotein hormone-rich fraction. These hormones are then further purified by ion exchange chromatography.

Roos et al. (1963) harvest their glycoprotein-rich 
fraction from the supernatant retrieved from the ammonium sulphate precipitation of growth hormone. By increasing the concentration of ammonium sulphate the FSH-LH-rich fraction is precipitated. Some TSH, however, precipitates with the growth hormone. Further purification of LH and FSH is achieved by chromatography on DEAE cellulose, gel filtration on Sephadex G100, adsorption chromatography on hydroxyapatite, and preparative polyacrylamide electrophoresis.

In the method of Jones et al. (1977) the pH 4.9 supernatant is found to be a rich source of glycoprotein hormones (McLean et al., 1977). Ammonium sulphate $(53 \mathrm{~g} / \mathrm{l})$ is added to the supernatant and protein precipitating between $50 \%$ and $75 \%$ ethanol is harvested. Initial chromatography is carried out on Sephadex G100, which, surprisingly, separates most of the LH activity from FSH and TSH. The LH is further purified on DEAE and CM-cellulose. FSH and TSH, after removal of the final traces of LH by DEAE cellulose chromatography, are separated on CM-cellulose. They are then further purified by rechromatography on CM-cellulose (Fig. 4).

\section{Corticotrophin (ACTH), lipotrophin (LPH), and} melanotrophin (MSH)

As $\alpha$-MSH and $\beta$-MSH do not seem to be present in the normal adult human pituitary tissue (Lowry and Scott, 1975) their purification will not be discussed. ACTH and LPH are extremely susceptible to proteolytic degradation and therefore care is needed during their isolation. The first preparation of purified human ACTH (molecular weight 4500 ) was achieved by Lerner et al. (1968). They used the ACTH-rich oxycellulose concentrate from the Raben procedure (for growth hormone) as their starting material. Adrenocorticotrophin is eluted off the oxycellulose with $0 \cdot 1 \mathrm{M}$ hydrochloric acid and freeze dried. Further purification is achieved by ion exchange chromatography on CM-cellulose and gel filtration on Sephadex G25 and G50. One major and several minor peptides were purified, all possessing similar amino-acid compositions and biological activity. Lipotrophin (molecular weight 10000) seems to be synthesised in the same cell as ACTH (Phifer et al., 1974) and also contains the heptapeptide sequence, which is seen at positions 4-10 in ACTH. Lipotrophin has been purified by several groups, notably Cseh et al. (1968), Scott and Lowry (1974), and Chretien et al. (1976). Scott and Lowry (1974) believe that the failure of themselves and other authors to identify human $\beta$-MSH in human pituitaries is because it comprises the 37-58 sequence of LPH and can be formed only during inappropriate extraction procedures. They also purified ACTH the same extraction method as for LPH and foun two forms. The more acidic form (which was separated on CM-cellulose) was identified deaminated ACTH by comparing amino-acid analysis of acid and enzyme hydrolysates.

\section{Hypothalamic hormones}

There are two main reasons why the hypothalamid hormones are so difficult to purify-their assay is quite difficult and their concentration in hyp 8 thalamic tissue is very low. Thus three putative hormones have yet to be chemically characterised $\stackrel{\omega}{\oplus}$ corticotrophin releasing factor (CRF), grow hormone releasing factor (GRF), and prolactin inhibiting factor (PIF). Three releasing factors, how ever, have been identified and characterised. They are growth hormone release-inhibiting hormongs (GH-RIH), or somatostatin (Brazeau et al., 1973థ; luteinizing hormone-releasing hormone (LH-RH) (Schally et al., 1971a); and thyrotrophin-releasing hormone (TRH) (Folkers et al., 1969). They are a small peptides varying from three (TRH) to thirtee (GH-RIH) amino-acids. More accurate and sensitive assay methods-for example, the perfused isolate rat pituitary cell column (Lowry, 1974; Gillies क्.n Lowry, 1976) and the cultured anterior pituitaryseg

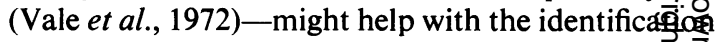
of the, as yet, uncharacterised factors.

Since the type of strategy adopted during the is\&్5 lation of these factors is somewhat similar only the outline of the isolation of LH-RH will be describet (Schally et al., 1971b). Hypothalamic tissue is vegy fatty and lyophilized fragments were extracted with acetone and chloroform-methanol to get a usabe powder. This was extracted with $2 \mathrm{M}$ acetic acid and the resulting freeze-dried powder was extracted with glacial acetic acid. This extract was subjected to gol filtration on Sephadex G25. Active fractions were pooled and desalted by extraction with phenol. Afte recovery the phenol-soluble materials were submit ted to ion exchange chromatography on CN cellulose. This chromatographic step was repeated. Further purification was achieved by free-flo electrophoresis, counter-current distribution, partit tion chromatography, repurification by partitiog chromatography in another solvent system, an finally, zone electrophoresis on a cellulose columfi. Only $830 \mu \mathrm{g}$ of material was recovered at the fingl stage from 165000 pig hypothalami weighing $2.5 \mathrm{~kg}$. This represents about a 3 million-fold concentratiof As there was not enough material for complete characterisation the same authors initiated a secong batch of nearly 500000 pig hypothalami and we successful in the complete characterisation of LI RH. (Schally et al., 1971b). 
TRH was isolated by Schally et al. (1966). Only three amino-acids were identified by acid hydrolysis of this pure TRH-glutamic acid, proline, and histidine in essentially equimolar amounts. As the peptide seemed to have both $\mathrm{N}$ - and $\mathrm{C}$-terminals blocked it was very difficult to characterise further. Consequently, various tripeptides were synthesised containing the three amino-acids in different sequence. One peptide, although somewhat impure but containing pyroglutamic acid at the $\mathrm{N}$-terminal and proline amide at the $\mathrm{C}$-terminal, was found to be active.

Isolation and chemical characterisation of these very scarce hypothalamic peptides has made their chemical synthesis possible. Thus they can now be used in both therapeutic and diagnostic procedures, which would be impossible if we had to rely on the amounts obtained from purification procedures.

\section{References}

Brazeau, P., Vale, W., Burgus, R., Ling, N., Butcher, M. Rivier, J., and Guillemin, R. (1973). Hypothalamic polypeptide that inhibits the secretion of immunoreactive pituitary growth hormone. Science, 179, 77.

Chretien, M., Gilardeau, C., Seidah, N., and Lis, M. (1976). Purification and partial characterisation of human pituitary lipolytic hormone. Canadian Journal of Biochemistry and Physiology, 54, 778.

Cseh, G., Graf, L., and Goth, F. (1968). Lipotropic hormone obtained from human pituitary glands. FEBS Letters, 2 , 42.

Folkers, K., Enzmann, F., Boler, J., Bowers, C. Y., and Schally, A. V. (1969). Discovery of modification of the synthetic tripeptide sequence of the thyrotropic releasing hormone having activity. Biochemical and Biophysical Research Communications, 37, 123.

Gillies, G., and Lowry, P. J. (1976). Investigation of corticotrophin releasing factor using the isolated rat pituitary cell column. Journal of Endocrinology, 71, 61P.

Hartree, A. S. (1966). Separation and partial purification of the protein hormones from human pituitary glands. Biochemical Journal, 100, 754.

Hwang, P., Guyda, H., and Friesen, H. (1972). Purification of human prolactin. Journal of Biological Chemistry, 247, 1955.

Jones, R. Lumley, Benker, G., Lloyd, T. J., Landon, J., and Lowry, P. J. (1977). Large-scale preparation of highly purified human growth hormone for clinical use. (In press).

Lerner, A. B., Upton, G. V., and Lande, S. (1968). Purification of porcine and human ACTH. In Pharmacology of Hormonal Polypeptides and Proteins (Advances in Experimental Medicine and Biology, Vol. 2), ed. N. Back,
L. Martini, and R. Paoletti. New York, Plenum Publishing.

Lewis, U. J., Singh, R. N. P., and Seavey, B. K. (1971). Human prolactin: isolation and some properties. Biochemical and Biophysical Research Communications, 44, 1169.

Lowry, P. J. (1974). A sensitive method for the detection of corticotrophin releasing factor using a perfused pituitary cell column. Journal of Endocrinology, 62, 163.

Lowry, P. J., and Scott, A. P. (1975). The evolution of vertebrate corticotrophin and melanocyte-stimulating hormone. General and Comparative Endocrinology, 26, 16.

McLean, C., Satgunasingam, N., and Lowry, P. J. (1977). Purification of glycoprotein hormones from frozen human pituitary glands. In press.

Mills, J. B., Ashworth, R. B., Wilhelmi, A. E., and Hartree, A. S. (1969). Improved method for the extraction and purification of human growth hormone. Journal of Clinical Endocrinology and Metabolism, 29, 1456.

Phifer, R. F., Orth, D. N., and Spicer, S. S. (1974). Specific demonstration of the human hypophyseal adrenocorticotrophic (ACTH/MSH) cell. Journal of Clinical Endocrinology and Metabolism, 39, 684.

Raben, M. S. (1959). Human growth hormone. Recent Progress in Hormone Research, 15, 71.

Roos, P. (1968). Human follicle-stimulating hormone. Acta Endocrinologica, 59, Supplement 131.

Roos, P., Fevold, H. R., and Gemzell, C. A. (1963). Preparation of human growth hormone by gel filtration. Biochemica et Biophysica Acta, 74, 525.

Schally, A. V., Arimura, A., Baba, Y., Nair, R. M. G., Matsuo, H., Redding, T. W., Debeljuk, L., and White, W. F. (1971a). Isolation and properties of the FSH and LH-releasing hormone. Biochemical and Biophysical Research Communications, 43, 393.

Schally, A. V., Arimura, A., Kastin, A. J., Matsuo, H., Baba, Y., Redding, T. W., Nair, R. M. G., and Debeljuk, L (1971b). Gonadotrophin-releasing hormone: one polypeptide regulates secretion of luteinizing and folliclestimulating hormones. Science, 173, 1036.

Schally, A. V., Bowers, C. Y., Redding, T. W., and Barrett, J. F. (1966). Isolation of thyrotropin releasing factor (TRF) from porcine hypothalamus. Biochemical and Biophysical Research Communications, 25, 165.

Scott, A. P., and Lowry, P. J. (1974). Adrencorticotrophic and melanocyte-stimulating peptides in the human pituitary. Biochemical Journal, 139, 593.

Vaitukaitus, J. L., and Ross, G. T. (1974). Subunits of human glycoproteins: their immunological and biological behaviour. In Heterogeneity of Polypeptide Hormones, ed D. Rabinowitz and J. Roth, p 98. Academic Press, New York and London.

Vale, W., Grant, G., Amoss, M., Blackwell, R., and Guillemin, R. (1972). Culture of enzymatically dispersed anterior pituitary cells: functional validation of a method. Endocrinology, 91, 562.

Wilhelmi, A. E. (1961). Fractionation of human pituitary glands. Canadian Journal of Biochemistry and Physiology, 39, 1659. 